\title{
How detrimental is reexploration for bleeding after cardiac surgery?
}

\author{
Marc Ruel, MD, MPH, ${ }^{a}$ Vincent Chan, MD, MPH, ${ }^{a}$ Munir Boodhwani, MD, MMSc, ${ }^{a}$ \\ Bernard McDonald, MD, PhD, ${ }^{\mathrm{b}}$ Xiaofang Ni, MD, ${ }^{\mathrm{a}}$ Gurinder Gill, MSc, CPC, ${ }^{\mathrm{a}}$ Khanh Lam, MD, MPH, ${ }^{\mathrm{a}}$ \\ Paul Hendry, MD, ${ }^{\mathrm{a}}$ Roy Masters, $\mathrm{MD},{ }^{\mathrm{a}}$ and Thierry Mesana, $\mathrm{MD}, \mathrm{PhD}^{\mathrm{a}}$
}

\begin{abstract}
Objective: To establish the risk factors and impact of reexploration for bleeding in a large modern cardiac surgical cohort.

Methods: At a tertiary referral center, baseline, index procedural, reexploration, outcome, and readmission characteristics of 16,793 consecutive adult cardiac surgery patients were prospectively entered into dedicated clinical databases. Correlates of reexploration for bleeding, as well as its association with outcomes and readmission, were examined with multivariable regression models.
\end{abstract}

Results: The mean patient age was $65.9 \pm 12.1$ years, and 11,991 patients (71.4\%) patients were male. Perioperative mortality was $2.8 \%$ (458 of 16,132) in those who did not undergo reexploration for bleeding and $12.0 \%$ (81 of 661) in those who underwent reexploration for bleeding, corresponding to an odds ratio of $3.4 \pm 0.5(P<.001)$ over other predictors of mortality, including Euroscore II. Mortality was highest in patients who underwent reexploration after the day of index surgery (odds ratio, $6.4 \pm 1.1$ ). Hospital stay was longer in patients who underwent reexploration for bleeding (median, 12 days, vs 7 days in patients who did not undergo reexploration; $P<.001$ ), to an extent beyond any other correlate. Reexploration for bleeding also was independently associated with new-onset postoperative atrial fibrillation, renal insufficiency, intensive care unit readmission, and wound infection. Risk factors for reexploration for bleeding were tricuspid valve repair, on-pump versus off-pump coronary artery bypass grafting, emergency status, cardiopulmonary bypass (CPB) duration, low body surface area, and lowest CPB hematocrit of $<24 \%$.

Conclusions: Reexploration for bleeding is a lethal and morbid complication of cardiac surgery, with a detrimental effect that surpasses that of any other known potentially modifiable risk factor. All efforts should be made to minimize the incidence and burden of reexploration for bleeding, including further research on transfusion management during CPB. (J Thorac Cardiovasc Surg 2017;154:927-35)

\begin{tabular}{|cccc|}
\hline & $\begin{array}{c}\text { Observed } \\
\text { Mortality (O) }\end{array}$ & $\begin{array}{c}\text { Expected } \\
\text { Mortality (E) }\end{array}$ & O/E Ratio \\
\hline $\begin{array}{c}\text { Not Re-Explored } \\
\text { for Bleeding }\end{array}$ & $2.8 \%$ & $4.1 \%$ & 0.7 \\
\hdashline $\begin{array}{c}\text { Re-Explored } \\
\text { for Bleeding }\end{array}$ & $12 \%$ & $6.7 \%$ & 1.8 \\
\hline
\end{tabular}

Reexploration for bleeding and perioperative mortality.

\section{Central Message}

Reexploration for bleeding, the correlates of which were examined here, brings an unfavorable reversal of the observed/expected ratio for a given patient. Continued efforts should be made to avoid its occurrence.

\section{Perspective}

In this study, reexploration for bleeding was associated with a 3.5 -fold increase in hospital mortality. Reexploration for bleeding performed after the day of operation had an even worse prognosis. These detrimental effects were additive to that of blood product transfusions. Reexploration for bleeding was associated with an unfavorable reversal of the observed/expected ratio for a given patient.

See Editorial Commentary page 936.
Heart operations often result in severe bleeding, and reexploration for bleeding remains a well-recognized complication of cardiac surgery, with a reported incidence ranging

\footnotetext{
From the Divisions of a Cardiac Surgery and ${ }^{b}$ Cardiac Anesthesia, University of Ottawa Heart Institute, Ottawa, Ontario, Canada.

This study was funded by the Division of Cardiac Surgery Endowed Research Chair, University of Ottawa Heart Institute.

Read at the 95th Annual Meeting of The American Association for Thoracic Surgery, Seattle, Washington, April 25-29, 2015.

Received for publication May 3, 2015; revisions received March 28, 2016; accepted for publication April 5, 2016.

Address for reprints: Marc Ruel, MD, MPH, Division of Cardiac Surgery, University of Ottawa Heart Institute, 40 Ruskin St, Suite 3402, Ottawa, Ontario, Canada (E-mail: mruel@ottawaheart.ca).

$0022-5223 / \$ 36.00$

Copyright (C) 2017 by The American Association for Thoracic Surgery http://dx.doi.org/10.1016/j.jtcvs.2016.04.097
}

from $2 \%$ to $6 \% .^{1-5}$ As such, previous studies have examined the relationship between transfusion and mortality after cardiac surgery, ${ }^{6}$ as well as the impact of the timing of reexploration, ${ }^{2,4}$ with several groups promoting earlier reintervention. In this study, we examined the risk factors and impact of reexploration for bleeding in a modern, consecutive cohort of patients that

Scanning this $\mathrm{QR}$ code will take you to the article title page. To view the AATS 2015 Webcast, see the URL next to the video thumbnail. 


$$
\begin{aligned}
& \text { Abbreviations and Acronyms } \\
& \text { BSA }=\text { body surface area } \\
& \text { CABG }=\text { coronary artery bypass grafting } \\
& \text { CI }=\text { confidence interval } \\
& \text { CPB }=\text { cardiopulmonary bypass } \\
& \text { ICU }=\text { intensive care unit } \\
& \text { IQR }=\text { interquartile range } \\
& \text { LV }=\text { left ventricular } \\
& \text { O/E }=\text { observed-to-expected } \\
& \text { OR }=\text { odds ratio } \\
& \text { ROC }
\end{aligned}
$$

encompassed all cardiac surgical procedures, while providing adjustments for baseline characteristics and risk.

We examined the correlates of reexploration for bleeding, and characterized its independent association with hospital outcomes and readmission, in a large consecutive cohort of patients who underwent cardiac surgery at a tertiary center. Our aim was to improve the understanding of reexploration for bleeding after cardiac surgery and to help surgeons, anesthesiologists, and intensive care specialists identify patients at risk for this complication, as well as possibly curtail some of its modifiable risk factors.

\section{METHODS \\ Patients and Definitions}

Figure 1 depicts the study flow chart. A total of 16,793 consecutive patients underwent an index adult cardiac surgical procedure performed by 1 of 11 surgeons at the University of Ottawa Heart Institute, between July 2, 2002, and September 23, 2014. Postoperatively, patients were cared for in a closed dedicated cardiac surgical intensive care unit (ICU) staffed by intensive care-trained cardiac anesthesiologists, and when stable were transferred to a cardiac surgery ward, where they recovered until discharge.

Data were prospectively entered into 4 dedicated databases, which were cross-referenced and complemented with one another with regard to accurate classification of the index operation, the occurrence of reexploration for bleeding, and the patients' baseline characteristics, including risk score. Operative priority was determined prospectively; urgent priority was an index cardiac operation deemed necessary during the same hospital admission that led to diagnosis or the latest reevaluation. Emergency priority indicated an operation performed either immediately or within 24 hours of diagnosis or a change in the patient's condition. In Figure 1, "heart failure" surgeries comprise heart transplantation, mechanical heart assistance/ventricular assist device, or other operations for cardiomyopathy, and "others" includes pericardiectomy, cardiac tumor resection, pulmonary thromboendarterectomy or embolectomy, and other noncategorized operations.

Surgery was performed with cardiopulmonary bypass (CPB) unless indicated otherwise; when applicable, the allocation of off-pump bypass surgery corresponded to the "as-treated" approach. For cardioplegia, crystalloid was used until June 2005, with blood cardioplegia used thereafter. An intraoperative intravenous tranexamic acid infusion protocol was used routinely unless contraindications, unusual circumstances, or personal

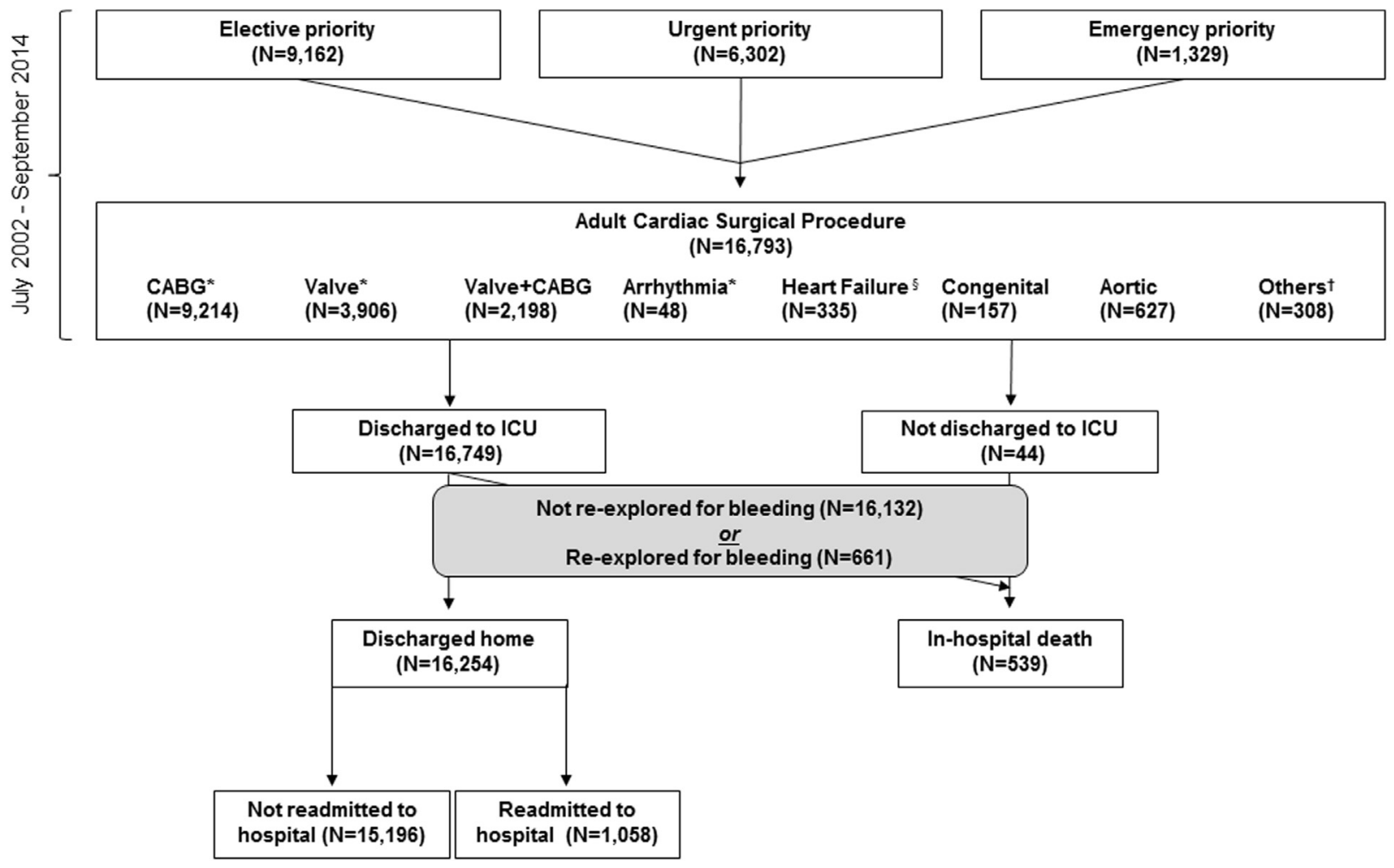

* Denotes isolated CABG, isolated valve replacement/repair, or isolated arrhythmia surgery

$\S$ Denotes heart transplantation, mechanical heart assistance, or other operations for cardiomyopathy

t Denotes pericardiectomy, cardiac tumor resection, pulmonary thromboendarterctomy or embolectomy, or other non-categorized operations

FIGURE 1. Study flow chart. $C A B G$, Cardiopulmonary bypass; $I C U$, intensive care unit. 
preferences dictated otherwise. Left ventricular (LV) grades 1, 2, 3, and 4 were defined as an ejection fraction of $\geq 50 \%, 35 \%$ to $49 \%, 20 \%$ to $34 \%$, and $<20 \%$, respectively. The increase in serum creatinine was defined as the highest serum creatinine value measured during the index admission minus the preoperative creatinine value. New atrial fibrillation indicated atrial fibrillation that was not previously known and that was noted postoperatively, necessitating observation, treatment, or prolonged hospitalization. Mortality was defined as hospital mortality at any time before institutional discharge after the index operation. Readmission referred specifically to this occurrence at our center. Surgical site infections were monitored during hospitalization and after discharge by dedicated trained personnel and entered prospectively into a separate database linked to perioperative data.

\section{Statistical Analysis}

Continuous data are presented as a mean \pm standard deviation, unless specified otherwise. Categorical variables are presented as number and percentage. Data were analyzed using Stata/IC versions 11 and 14 (StataCorp, College Station, Tex). Comparisons between the patients who did not undergo reexploration for bleeding and those did undergo reexploration for bleeding were performed using the unpaired $t$ test or the Mann-Whitney $U$ test for continuous variables. Categorical variables were compared using the $\chi^{2}$ test, with Yates correction where appropriate. Statistical significance was set at $P<.05$, and Bonferroni corrections were not applied.

As correlates of clinical outcomes (ie, reexploration for bleeding, mortality, morbidity, and length of stay), the following variables were simultaneously forced into logistic (for reexploration for bleeding, mortality, other morbidity, and readmission) or linear (for increases in serum creatinine and length of stay) regression models: age, sex, body surface area (BSA), preoperative atrial fibrillation, preoperative LV grade, preoperative serum creatinine, operative priority, redo status, type of operation, lowest hematocrit on CPB, durations of aortic cross-clamping and CPB, number of blood product units transfused, postoperative increase in serum creatinine, and new-onset atrial fibrillation. For an additional individual variable term to be incorporated into a given model, its multivariable $P$ value had to be $<.05$, the cumulative $\chi^{2}$ (logistic) or F (linear) distribution value had to increase, and the model probability $\left(<\chi^{2}\right.$ or $\left.<F\right)$ had to remain statistically significant. ICU and hospital lengths of stay were also analyzed by logarithmic transformation. The effect of timing of the first occurrence of reexploration for bleeding was examined using a dichotomous term (day of surgery vs a later date).

The Euroscore II was determined prospectively from 2011 onward, and completed retrospectively, using prospectively entered and regularly audited data elements, for patients who underwent surgery before 2011 . Analyses by surgeons used the Euroscore II to determine each individual observed-to-expected (O/E) mortality ratio, and examined the multivariable association of each surgeon (A to $\mathrm{K}$ ) on reexploration for bleeding and its impact on perioperative mortality.

Optimal cutoff values for the ability of lowest hematocrit value on CPB to predict reexploration for bleeding were determined, by means of receiver operating characteristics (ROC), as the closest point to the best point (specificity, 1 ; sensitivity, 1 ) on the ROC curve. All reported $P$ values are 2-sided.

\section{RESULTS}

\section{Patient Characteristics}

The mean patient age was $65.9 \pm 12.1$ years (range, 15 to 99 years) at the time of surgery, and 11,991 of the patients $(71.4 \%)$ were male. The mean Euroscore II was 4.2 $\pm 6.9 \%$ (range, $0.5 \%$ to $77.6 \%$ ). Reexploration after the index procedure was performed in 710 patients $(4.2 \%)$, in $661(3.9 \%)$ for reexploration for bleeding. The first episode of reexploration for bleeding occurred on the operative day in 358 patients $(54.2 \%)$, on the first postoperative day in $169(25.6 \%)$, on the second postoperative day in 19 $(2.9 \%)$, on postoperative days $3-7$ in 47 patients $(7.1 \%)$, during the second postoperative week in $47(7.1 \%)$, and beyond the second postoperative week in 21 patients $(3.2 \%)$. Thirteen patients $(2.0 \%$ of those who underwent reexploration for bleeding) had more than one reexplorations for bleeding.

Table 1 presents perioperative patient characteristics in the patients who did and did not undergo reexploration for bleeding. Reexploration for bleeding was more common in patients with lower BSA, poorer LV grade, redo operations, and emergency operations. The occurrence of reexploration for bleeding correlated both with cardiopulmonary bypass $(\mathrm{CPB})$ and aortic cross-clamp durations.

\section{Correlates of Reexploration for Bleeding}

On multivariable analysis, independent correlates of reexploration for bleeding were low BSA, emergency status, redo status, tricuspid valve repair, operation for aortic dissection, on-pump versus off-pump coronary artery bypass grafting (CABG), durations of $\mathrm{CPB}$ and aortic cross-clamping, and lowest $\mathrm{CPB}$ hematocrit value (Table 2). Comparison of ROC curves (not shown) revealed the best cutoff for lowest CPB hematocrit value as $27 \%$ (c-statistic, 0.614); however, specificity was increased in patients with a lowest CPB hematocrit of $<24 \%$, in whom the rate of reexploration was independently increased by two-thirds (odds ratio [OR], $1.7 \pm 0.2$; $P<.001)$.

Reexploration for bleeding was not significantly predicted by age (OR, $1.008 \pm 0.005$ per year; $P=.10)$, $\mathrm{LV}$ grade $(\mathrm{OR}, 1.1 \pm 0.1 ; P=.10)$, preoperative atrial fibrillation (OR, $1.2 \pm 0.2 ; P=.30$ ), serum creatinine level (OR, $1.0007 \pm 0.0007$ per $\mu \mathrm{mol} / \mathrm{L} ; P=.30)$, or preoperative hematocrit $(0.77 \pm 0.33$ per $\% ; P=.5)$.

\section{Impact of Reexploration for Bleeding and Its Timing on Mortality}

Perioperative mortality was $2.8 \%$ (458 of 16,132$)$ in patients who did not undergo reexploration for bleeding and $12.0 \%$ (81 of 661 ) in those who underwent reexploration for bleeding, resulting in a reversal of the O/E mortality ratio in patients who underwent reexploration for bleeding (Figure 2 and Table 3). In a multivariable model that incorporated significant risk factors for mortality and Euroscore II, reexploration for bleeding was independently associated with an OR of $3.4 \pm 0.5(P<.001)$ for perioperative death, which was additive to that of other mortality correlates, including the number of blood product units transfused (Table 4).

The timing of reexploration for bleeding was also significantly associated with mortality. Using the same 
TABLE 1. Patient characteristics according to reexploration for bleeding status

\begin{tabular}{|c|c|c|c|}
\hline Characteristic & Not reexplored for bleeding $(\mathrm{n}=\mathbf{1 6 , 1 3 2})$ & Reexplored for bleeding $(n=661)$ & $P$ value \\
\hline Female sex, n $(\%)$ & $4631(28.7)$ & $171(28.6)$ & .11 \\
\hline Age, $y$, mean \pm SD & $65.9 \pm 12.1$ & $66.5 \pm 12.7$ & .19 \\
\hline $\mathrm{BSA}, \mathrm{m}^{2}$, mean $\pm \mathrm{SD}$ & $1.92 \pm 0.24$ & $1.88 \pm 0.25$ & .002 \\
\hline \multicolumn{4}{|l|}{ LV grade, $n(\%)^{*}$} \\
\hline I & $6476(67.6)$ & $235(65.1)$ & .01 \\
\hline II & 1693 (17.7) & $59(16.3)$ & \\
\hline III & $1030(10.7)$ & $40(11.1)$ & \\
\hline IV & $387(4.0)$ & $27(7.5)$ & \\
\hline Atrial fibrillation, n (\%) & $1685(10.5)$ & 83 (12.6) & .08 \\
\hline Serum creatinine, $\mu \mathrm{mol} / \mathrm{L}$, mean $\pm \mathrm{SD}$ & $100.4 \pm 71.7$ & $107.7 \pm 71.5$ & .05 \\
\hline Redo status, n (\%) & $1212(7.5)$ & $81(12.3)$ & $<.001$ \\
\hline \multicolumn{4}{|l|}{ Operative priority, n (\%) } \\
\hline Elective & $8859(54.9)$ & $303(45.8)$ & $<.001$ \\
\hline Urgent & $6040(37.4)$ & $262(39.6)$ & \\
\hline Emergency & $1233(7.6)$ & $96(14.5)$ & \\
\hline Euroscore II, mean $\pm \mathrm{SD}$ & $4.1 \pm 6.7$ & $6.7 \pm 6.9$ & $<.001$ \\
\hline \multicolumn{4}{|l|}{ Type of surgery, n (\%) } \\
\hline $\mathrm{CABG}^{\dagger}$ & $8966(55.6)$ & $248(37.5)$ & $<.001$ \\
\hline Valve $\dagger$ & $3744(23.2)$ & $162(24.5)$ & \\
\hline Valve + CABG & $2065(12.8)$ & $133(20.1)$ & \\
\hline Arrhythmia $\dagger$ & $48(0.3)$ & 0 & \\
\hline Heart failure $\ddagger$ & $295(1.8)$ & $40(6.1)$ & \\
\hline Congenital & $152(0.9)$ & $5(0.8)$ & \\
\hline Aortic & $577(3.6)$ & $50(7.6)$ & \\
\hline Other $\S$ & $285(1.8)$ & $23(3.5)$ & \\
\hline $\mathrm{CPB}$ duration, min, mean $\pm \mathrm{SD}$ & $102.8 \pm 54.1$ & $133.4 \pm 74.5$ & $<.001$ \\
\hline Aortic clamp duration, min, mean $\pm \mathrm{SD}$ & $66.3 \pm 34.2$ & $82.7 \pm 41.8$ & $<.001$ \\
\hline Lowest $\mathrm{CPB}$ hematocrit, $\%$, mean \pm SD & $28.6 \pm 4.8$ & $27.4 \pm 5.1$ & $<.001$ \\
\hline
\end{tabular}

$\overline{S D}$, Standard deviation; $B S A$, body surface area; $L V$, left ventricular; $C A B G$, coronary artery bypass grafting; $C P B$, cardiopulmonary bypass. *Preoperative LV function records were available for 9947 patients. Grade I, ejection fraction $\geq 50 \%$; grade II, ejection fraction $35 \%$ to $49 \%$; grade III, ejection fraction $20 \%$ to $34 \%$; grade IV, ejection fraction $<20 \%$. †Isolated CABG, isolated valve replacement/repair, or isolated arrhythmia surgery. $\ddagger$ Heart transplantation, mechanical heart assistance, or other operations for cardiomyopathy. §Pericardiectomy, cardiac tumor resection, pulmonary thromboendarterctomy or embolectomy, or other noncategorized operations.

multivariable model, reexploration for bleeding on the day of surgery was associated with an OR of $2.0 \pm 0.4$ (95\% confidence interval $[\mathrm{CI}], 1.3$ to $3.1 ; P<.001)$ for

TABLE 2. Independent determinants of reexploration for bleeding

\begin{tabular}{|c|c|c|}
\hline Determinant & $\begin{array}{c}\text { Coefficient, } \\
\text { mean } \pm \text { SD }(95 \% \text { CI })\end{array}$ & $\begin{array}{c}P \\
\text { value }\end{array}$ \\
\hline Body surface area (per $\mathrm{m}^{2}$ ) & $0.6 \pm 0.1(0.4-0.9)$ & .02 \\
\hline Emergency status & $1.7 \pm 0.4(1.1-2.6)$ & .03 \\
\hline Redo status & $1.5 \pm 0.3(1.1-2.1)$ & .02 \\
\hline Euroscore II* & $1.03 \pm 0.01(1.02-1.04)$ & $<.001$ \\
\hline $\begin{array}{l}\text { On-pump vs off-pump coronary } \\
\text { artery bypass grafting }\end{array}$ & $1.7 \pm 0.1(1.1-2.5)$ & .02 \\
\hline Tricuspid valve repair & $2.6 \pm 0.1(1.9-3.6)$ & $<.001$ \\
\hline Aortic dissection repair & $3.0 \pm 1.0(1.6-5.6)$ & .001 \\
\hline $\begin{array}{l}\text { Lowest cardiopulmonary } \\
\text { bypass hematocrit (per \%) }\end{array}$ & $0.97 \pm 0.01(0.94-0.99)$ & .02 \\
\hline Aortic clamp duration (per min) & $1.003 \pm 0.001(1.000-1.006)$ & .04 \\
\hline $\begin{array}{l}\text { Cardiopulmonary bypass } \\
\text { duration (per } \mathrm{min} \text { ) }\end{array}$ & $1.005 \pm 0.001(1.003-1.006)$ & $<.001$ \\
\hline
\end{tabular}

perioperative death, whereas reexploration for bleeding performed after the day of surgery had a 3-fold greater correlation with mortality $(P<.001)$, with an OR of $6.4 \pm 1.1$ for perioperative death $(95 \% \mathrm{CI}, 4.7$ to $8.9 ; P<.001)$.

Mortality was not independently associated with BSA (OR, $1.2 \pm 0.4$ per $\mathrm{m}^{2} ; P=.60$ ), preoperative atrial fibrillation (OR, $1.3 \pm 0.2 ; P=.20$ ), type of operation other than specified in Table 4 (ORs not shown), on-pump versus off-pump CABG (OR, $0.99 \pm 1.02 ; P=1.0)$, or the development of new atrial fibrillation postoperatively (OR, $1.04 \pm 0.2 ; P=.80$ ).

\section{Mortality Impact of Reexploration for Bleeding: Analysis by Surgeon}

The index operations were performed by 11 surgeons (identified as A to K), who had a Euroscore II O/E mortality ratio ranging between 0.31 and 1.11 over the study period, with an overall population O/E ratio of 0.76 . Surgeons themselves had ORs ranging from 0.7 to $1.4(P<.001)$ with regard to independently predicting the occurrence of reexploration for bleeding. Regardless of the surgeon, 


\begin{tabular}{lccc} 
& $\begin{array}{c}\text { Observed } \\
\text { Mortality (O) }\end{array}$ & $\begin{array}{c}\text { Expected } \\
\text { Mortality (E) }\end{array}$ & O/E Ratio \\
\hline $\begin{array}{c}\text { Not Re-Explored } \\
\text { for Bleeding }\end{array}$ & $2.8 \%$ & $4.1 \%$ & 0.7 \\
$\begin{array}{c}\text { Re-Explored } \\
\text { for Bleeding }\end{array}$ & $12 \%$ & $6.7 \%$ & 1.8 \\
\hline
\end{tabular}

FIGURE 2. Reexploration for bleeding and perioperative mortality. $O / E$, Observed-to-expected.

however, the occurrence of reexploration for bleeding was significantly correlated with mortality, and surgeon identity did not significantly alter this statistically significant OR of 3.4 for mortality.

\section{Impact of Reexploration for Bleeding on Postoperative Complications, Length of Stay, and Readmission}

Median length of stay in the ICU (by 2 days compared with patients who did not have reexploration for bleeding; $P<.0001$ ) and hospital (by 5 days; $P<.0001$ ) were markedly increased by reexploration for bleeding to an extent beyond any other predictor, including new postoperative atrial fibrillation (hospital length of stay increase by 2 days; $P$ $<.0001$ ) (Table 5). Reexploration for bleeding also was independently associated with ICU readmission, greater postoperative increase in serum creatinine, postoperative atrial fibrillation, and incidence of surgical site infection. On the other hand, reexploration for bleeding did not significantly increase the incidence of hospital readmission.

\section{DISCUSSION}

This study reports on, to our knowledge, the largest clinical series to date of patients characterized in terms of reexploration for bleeding after cardiac surgery. We found that reexploration for bleeding had an incidence of $3.9 \%$, and the independent association of reexploration for bleeding with hospital mortality was approximately a 3.5-fold greater compared with no reexploration for bleeding. Important results from this study include the finding that reexploration for bleeding after the day of operation is associated with even worse prognosis, correlating with a 6.4-fold increase in the risk of death. In contrast to previous work, in the present study, the detrimental effect observed with reexploration for bleeding was additive to that of blood product transfusions. Furthermore, reexploration for bleeding was associated with an unfavorable reversal of the $\mathrm{O} / \mathrm{E}$ ratio for a given patient and, when it occurred, its significant correlation with death was not affected by surgeon identity.

Reexploration for bleeding was associated with significantly prolonged length of stay, higher incidence of postoperative atrial fibrillation, greater increases in serum creatinine, more ICU readmissions, and more frequent wound infections. Conversely, reexploration for bleeding was not associated with an increased likelihood of hospital readmission, suggesting that its observed detrimental effects were acute and due to the event itself rather than to baseline patient characteristics.

Correlates of reexploration for bleeding were low BSA, emergency status, redo status, tricuspid valve repair, on-pump versus off-pump CABG, longer durations of $\mathrm{CPB}$ and aortic cross-clamping, and a lowest hematocrit value on $\mathrm{CPB}$ of $<24 \%$, which was independently associated with a $67 \%$ increase in the risk of reexploration for bleeding. On the other hand, reexploration for bleeding was not predicted by age, LV grade, preoperative atrial fibrillation, creatinine level, or preoperative hematocrit. Taken together, these results indicate that reexploration for bleeding is one of the most important areas of focus for decreasing mortality and morbidity in cardiac surgery, given that few, if any, other potentially preventable complications are associated with such high mortality and morbidity.

Reexploration for bleeding has been the subject of numerous publications in the cardiac surgery literature. Our findings reported herein confirm some previously reported associations, such as between reexploration for bleeding and $\mathrm{BSA}^{7}{ }^{7}$ emergency status, renal insufficiency, ICU readmission, ${ }^{8}$ and wound infection. ${ }^{9-11}$ However, the independent mortality impact of reexploration for bleeding is controversial, ${ }^{5,6,12}$ with several groups claiming that blood transfusions are the true culprit, ${ }^{6}$ and that reexploration for bleeding, if performed early, may have a neutral or even favorable impact ${ }^{2,13,14}$ and thus not increase mortality. ${ }^{4}$ In the present large and inclusive series of consecutive, all-comer patients, we confirmed that the correlation of reexploration with mortality was additive to that of the number of blood units transfused, extended beyond Euroscore II predictions, and was independent of

TABLE 3. Impact of reexploration for bleeding on observed-to-expected mortality ratio

\begin{tabular}{lcc}
\hline \multicolumn{1}{c}{ Group } & $\begin{array}{c}\text { Expected mortality (E) by } \\
\text { Euroscore II, \% }\end{array}$ & \multicolumn{2}{c}{$\begin{array}{c}\text { Observed } \\
\text { mortality (O), \% }\end{array}$} \\
\hline Not reexplored for bleeding & $4.1 \pm 6.7$ & $2.8(458$ of 16,132$)$ \\
Reexplored for bleeding & $6.7 \pm 9.9$ & $12.0(81$ of 661$)$ \\
All patients & $4.2 \pm 6.9$ & $3.2(539$ of 16,793$)$ \\
\hline
\end{tabular}


TABLE 4. Independent determinants of perioperative mortality

\begin{tabular}{|c|c|c|}
\hline Determinant & Coefficient, mean \pm SD $(95 \%$ CI $)$ & $P$ value \\
\hline Female sex & $1.6 \pm 0.1(1.4-1.8)$ & $<.001$ \\
\hline Age (per y) & $1.04 \pm 0.04(1.03-1.05)$ & $<.001$ \\
\hline Euroscore II* & $1.06 \pm 0.01(1.05-1.07)$ & $<.001$ \\
\hline Left ventricular grade (per grade) & $1.6 \pm 0.1(1.4-1.8)$ & $<.001$ \\
\hline Creatinine (preoperative, per $\mu \mathrm{mol} / \mathrm{L}$ ) & $1.002 \pm 0.0006(1.001-1.003)$ & .001 \\
\hline Emergency status & $4.3 \pm 0.8(3.1-6.2)$ & $<.001$ \\
\hline Redo status & $1.5 \pm 0.3(1.1-2.1)$ & .02 \\
\hline Aortic dissection & $9.9 \pm 5.3(3.5-28.0)$ & $<.001$ \\
\hline Mitral valve repair & $0.6 \pm 0.1(0.4-0.9)$ & .007 \\
\hline Tricuspid valve repair & $1.9 \pm 0.4(1.3-2.8)$ & .001 \\
\hline Lowest cardiopulmonary bypass hematocrit (per \%) & $0.97 \pm 0.01(0.94-0.99)$ & .02 \\
\hline Aortic clamp duration (per min) & $1.01 \pm 0.002(1.01-1.02)$ & $<.001$ \\
\hline Cardiopulmonary bypass duration (per min) & $1.01 \pm 0.002(1.01-1.02)$ & $<.001$ \\
\hline Intraoperative transfusion & $1.4 \pm 0.2(1.2-1.8)$ & .001 \\
\hline Number of blood product units transfused intraoperatively & $1.02 \pm 0.003(1.02-1.03)$ & $<.001$ \\
\hline Reexploration for bleeding & $3.4 \pm 0.6(2.6-4.6)$ & $<.001$ \\
\hline
\end{tabular}

$S D$, Standard deviation; $C I$, confidence interval. *Except for reexploration for bleeding, Euroscore II was entered separately into the model, because it is collinear to patient-, cardiac- and operation-related factors.

surgeon, and that the timing of reopening significantly modified the detrimental impact of reexploration for bleeding, with reexploration performed after the day of the index operation associated with a 3-fold greater risk of mortality compared with reexploration performed on the day of surgery. Interestingly, the independent OR for mortality associated with reexploration for bleeding in this study paralleled that reported by Binacari and colleagues, ${ }^{1}$ who in a large meta-analysis of the impact of reexploration for bleeding in more than 500,000 patients, obtained a pooled relative risk of $4.3(95 \% \mathrm{CI}, 3.1$ to 6.0 ), compared to the OR of $3.4 \pm 0.5$ in the present study.

Another new finding was that lowest hematocrit value during CPB was a correlate of reexploration for bleeding. In another series, Loor and colleagues ${ }^{15}$ reported the adverse effects of low hematocrit during CPB, particularly when a value of $<25 \%$ was combined with the need for blood transfusions. In the present study, a nadir hematocrit of $<24 \%$ during $\mathrm{CPB}$ was independently correlated with subsequent reexploration for bleeding $(\mathrm{OR}, 1.7)$.

\section{Clinical Implications}

Nearly all cardiac surgical units are taking measures to avoid reexploration for bleeding after cardiac surgery, and this overarching goal has generated countless attempts at pharmacologic and procedural research of ways to decrease bleeding during and after cardiac surgery. Our present findings indicate that reexploration for bleeding remains prevalent and is one of the most lethal complication of cardiac surgery, and thus should be avoided at all costs. Potentially modifiable correlates may include maintaining a hematocrit of $\geq 24 \%$ or higher during CPB, favoring early (ie, day of surgery) over later reexploration, along with continued refinement of quality improvement programs and research into pharmacologic, technical, and biological adjuncts to minimize reexploration for bleeding after cardiac surgery. Notably, a recent randomized controlled trial comparing a restrictive and a liberal transfusion strategy revealed lower mortality and fewer adverse events with the liberal strategy, providing external credence to the CPB hematocrit threshold hypothesis uncovered in this study. ${ }^{16}$

TABLE 5. Postoperative length of stay and morbidity by reexploration for bleeding status

\begin{tabular}{|c|c|c|c|c|}
\hline Variable & $\begin{array}{c}\text { Not reexplored for } \\
\text { bleeding }(n=16,132)\end{array}$ & $\begin{array}{c}\text { Reexplored for } \\
\text { bleeding }(\mathrm{n}=661)\end{array}$ & $\begin{array}{c}\text { Multivariable } \\
\text { coefficient or } O R^{*}\end{array}$ & $\begin{array}{c}\text { Multivariable } \\
P \text { value* }\end{array}$ \\
\hline ICU LOS, d, median (IQR) $\dagger$ & $1(1)$ & $3(5)$ & Coefficient: $6.1 \pm 1.1$ & $<.001$ \\
\hline ICU readmission, $\mathrm{n}(\%)$ & $453(2.8)$ & $80(12.1)$ & OR: $3.6 \pm 0.8$ & $<.001$ \\
\hline New atrial fibrillation, $\mathrm{n}(\%)$ & $4194(26.0)$ & $240(36.3)$ & OR: $1.5 \pm 0.2$ & $.006 \dagger$ \\
\hline Increase in creatinine, umol/L, mean $\pm \mathrm{SD}$ & $25.9 \pm 48.5$ & $51.0 \pm 49.6$ & Coefficient: $17.9 \pm 3.2$ & $<.001$ \\
\hline Hospital LOS, d, median (IQR) $\dagger$ & $7(6)$ & $12(20)$ & Coefficient: $6.8 \pm 0.8$ & $<.001$ \\
\hline Hospital readmission, $\mathrm{n}(\%)$ & $1011(6.3)$ & $47(7.1)$ & OR: $1.02 \pm 0.3$ & .90 \\
\hline Surgical site infection, $\mathrm{n}(\%)$ & $1055(6.5)$ & $84(12.7)$ & OR: $2.0 \pm 0.4$ & .001 \\
\hline
\end{tabular}

$O R$, Odds ratio; $I C U$, intensive care unit; $L O S$, length of stay; $I Q R$, interquartile range; $S D$, standard deviation. *Multivariable models simultaneously included sex, age, preoperative creatinine, left ventricular grade, type of operation, emergency status, redo status, and new atrial fibrillation. $\dagger$ Also analyzed after logarithmic transformation. Equivalent results were obtained and are not reported. 
It is important to emphasize that the present study is observational and thus hypothesis-generating. For instance, it is possible that anemia on CPB may be related to dilutional coagulopathy or increased cardiac output, both of which are associated with increased propensity for bleeding. We cannot recommend targeted therapy to maintain a hematocrit of $24 \%$ during CPB based solely on the results of the present study.

\section{Limitations}

Because our data reflect routine clinical practice at only a single institution, this study carries the possibility of biases in patient, surgeon, or center selection, as well as in transfusion triggers. The use of multiple statistical tests increased the probability that associations might have been due to chance alone. Postdischarge deaths that may have occurred before the end of 30 days postsurgery were not included. We did not perform an economic analysis; however, Christensen and colleagues ${ }^{17,18}$ previously reported that the costs of excessive postoperative hemorrhage in cardiac surgery are substantial and correlate with a significant risk of postoperative complications and death. We did not evaluate the impact of perioperative temperature management. We also did not examine the effects of preoperative medications such as antiplatelet and antithrombotic agents, which are well known to increase the propensity for reexploration for bleeding and complications after cardiac surgery, ${ }^{19-22}$ but appear safe early after $\mathrm{CABG}^{23}$ (except in the case of antithrombotic agents). ${ }^{24}$ Importantly, we did not differentiate between surgical and coagulopathy bleeding, a distinction fraught with considerable overlap and error, although coagulopathy has been suggested to be associated with worse outcomes. ${ }^{25,26}$ Thus, our findings are associative and not causative, with no therapeutic proof suggesting, for instance, that avoid specific CPB hematocrit nadirs will affect reexploration for bleeding and mortality.

Throughout the study period, our unit generally followed some basic guidelines regarding the management of bleeding during and after cardiac surgery: continuation of aspirin up to the day of operation (unless contraindicated); discontinuation of clopidogrel 2 to 5 days before the operation (with the exception of emergency patients, those with a recent drug-eluting stent in a coronary artery that will not be grafted, and, increasingly since 2012, those with acute coronary syndrome); and attempts at full reversal of known coagulopathy intraoperatively and postoperatively (including the use of point-of-care testing since 2008 and factor concentrates as a last resort in complex or emergent cases). The following indications for reexploration for bleeding were generally applied: chest tube output $\geq 500 \mathrm{~mL} /$ hour, chest tube output $\geq 250 \mathrm{~mL} /$ hour for 4 hours, significant hemodynamic compromise that may relate to bleeding, and imaging evidence of a large clot $(\geq 4 \mathrm{~cm})$, a large pericardial collection $(\geq 3 \mathrm{~cm}$, particularly if circumferential), cardiac chamber compression, or large hemothorax.

\section{CONCLUSIONS}

Reexploration for bleeding is a non-infrequent, lethal, and potentially modifiable complication of cardiac surgery. It independently adds to other well known risk factors for mortality and morbidity, including the detrimental effects of blood transfusions. Reexploration for bleeding is associated with particularly lethal consequences if it occurs after the day of surgery, and its correlation with mortality, including a reversal of the $\mathrm{O} / \mathrm{E}$ mortality ratio at our unit, appears to be independent of surgeon identity. Our data suggest that avoiding a nadir hematocrit of $<24 \%$ during $\mathrm{CPB}$ could help preclude reexploration for bleeding, and may be particularly warranted in patients with other risk factors for reexploration for bleeding, such as those undergoing emergency or redo surgery, aortic dissection repair, or tricuspid valve repair or who have prolonged CPB duration. Finally, our present findings strongly justify continued quality improvement and research efforts by the cardiac surgical and anesthesia community to minimize the occurrence and negative impacts of reexploration for bleeding on patient outcomes.

\section{Webcast}

You can watch a Webcast of this AATS meeting presentation by going to: http://webcast.aats.org/2015/Video/ Monday/04-27-15_608_1445_Ruel.mp4.

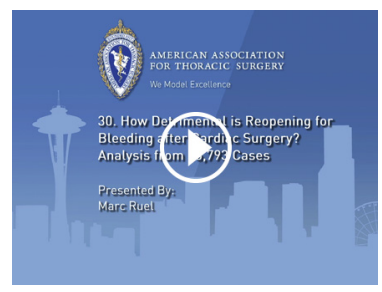

\section{Conflict of Interest Statement}

Authors have nothing to disclose with regard to commercial support.

\section{References}

1. Biancari F, Mikkola R, Heikkinen J, Lahtinen J, Airaksinen KE, Juvonen T. Estimating the risk of complications related to re-exploration for bleeding after adult cardiac surgery: a systematic review and meta-analysis. Eur J Cardiothorac Surg. 2012;41:50-5.

2. Karthik S, Grayson AD, McCarron EE, Pullan DM, Desmond MJ. Reexploration for bleeding after coronary artery bypass surgery: risk factors, outcomes, and the effect of time delay. Ann Thorac Surg. 2004;78:527-34; discussion 534.

3. Wolfe R, Bolsin S, Colson M, Stow P. Monitoring the rate of re-exploration for excessive bleeding after cardiac surgery in adults. Qual Saf Health Care. 2007 16:192-6. 
4. Haneya A, Diez C, Kolat P, Suesskind-Schwendi M, Ried M, Schmid C, et al. Reexploration for bleeding or tamponade after cardiac surgery: impact of timing and indication on outcome. Thorac Cardiovasc Surg. 2015;63:51-7.

5. Moulton MJ, Creswell LL, Mackey ME, Cox JL, Rosenbloom M. Reexploration for bleeding is a risk factor for adverse outcomes after cardiac operations. J Thorac Cardiovasc Surg. 1996;111:1037-46.

6. Ranucci M, Bozzetti G, Ditta A, Cotza M, Carboni G, Ballotta A. Surgical reexploration after cardiac operations: why a worse outcome? Ann Thorac Surg. 2008;86:1557-62.

7. Le-Bert G, Santana O, Pineda AM, Zamora C, Lamas GA, Lamelas J. The obesity paradox in elderly obese patients undergoing coronary artery bypass surgery. Interact Cardiovasc Thorac Surg. 2011;13:124-7.

8. Litmathe J, Kurt M, Feindt P, Gams E, Boeken U. Predictors and outcome of ICU readmission after cardiac surgery. Thorac Cardiovasc Surg. 2009;57: $391-4$

9. Filsoufi F, Castillo JG, Rahmanian PB, Broumand SR, Silvay G, Carpentier A, et al. Epidemiology of deep sternal wound infection in cardiac surgery. $J$ Cardiothorac Vasc Anesth. 2009;23:488-94.

10. Lu JC, Grayson AD, Jha P, Srinivasan AK, Fabri BM. Risk factors for sternal wound infection and mid-term survival following coronary artery bypass surgery. Eur J Cardiothorac Surg. 2003;23:943-9.

11. Salehi Omran A, Karimi A, Ahmadi SH, Davoodi S, Marzban M, Movahedi N, et al. Superficial and deep sternal wound infection after more than 9000 coronary artery bypass graft $(\mathrm{CABG})$ : incidence, risk factors and mortality. BMC Infect Dis. 2007;7:112.

12. Christensen MC, Dziewior F, Kempel A, von Heymann C. Increased chest tube drainage is independently associated with adverse outcome after cardiac surgery J Cardiothorac Vasc Anesth. 2012;26:46-51.

13. Kristensen KL, Rauer LJ, Mortensen PE, Kjeldsen BJ. Reoperation for bleeding in cardiac surgery. Interact Cardiovasc Thorac Surg. 2012;14:709-13.

14. Čanádyová J, Zmeko D, Mokráček A. Re-exploration for bleeding or tamponade after cardiac operation. Interact Cardiovasc Thorac Surg. 2012;14:704-7.

15. Loor G, Rajeswaran J, Li L, Sabik JF III, Blackstone EH, McCrae KR, et al. The least of 3 evils: exposure to red blood cell transfusion, anemia, or both? J Thorac Cardiovasc Surg. 2013;146:1480-7.e6.

16. Murphy GJ, Pike K, Rogers CA, Wordsworth S, Stokes EA, Angelini GD, et al. Liberal or restrictive transfusion after cardiac surgery. N Engl J Med. 2015;372: 997-1008.

17. Christensen MC, Krapf S, Kempel A, von Heymann C. Costs of excessive postoperative hemorrhage in cardiac surgery. J Thorac Cardiovasc Surg. 2009;138:687-93.

18. Alström U, Levin LA, Ståhle E, Svedjeholm R, Friberg O. Cost analysis of reexploration for bleeding after coronary artery bypass graft surgery. Br J Anaesth 2012;108:216-22.

19. Guay J, Andrew Ochroch E. Continuing antiplatelet therapy before cardiac surgery with cardiopulmonary bypass: a meta-analysis on the need for reexploration and major outcomes. J Cardiothorac Vasc Anesth. 2014;28:90-7.

20. Alghamdi AA, Moussa F, Fremes SE. Does the use of preoperative aspirin increase the risk of bleeding in patients undergoing coronary artery bypass grafting surgery? Systematic review and meta-analysis. J Card Surg. 2007;22:247-56.

21. Hansson EC, Rexius H, Dellborg M, Albertsson P, Jeppsson A. Coronary artery bypass grafting-related bleeding complications in real-life acute coronary syndrome patients treated with clopidogrel or ticagrelor. Eur J Cardiothorac Surg. 2014;46:699-705; discussion 705.

22. Jones HU, Muhlestein JB, Jones KW, Bair TL, Lavasani F, Sohrevardi M, et al. Preoperative use of enoxaparin compared with unfractionated heparin increases the incidence of re-exploration for postoperative bleeding after open-heart surgery in patients who present with an acute coronary syndrome: clinical investigation and reports. Circulation. 2002;106(12 Suppl 1):I19-22.

23. Chan V, Kulik A, Bourke ME, Ressler L, Mesana TG, Ruel M. Clopidogrel is safe early after on- and off-pump coronary artery bypass surgery. J Card Surg. 2007; 22:493-7.

24. Jones HU, Muhlestein JB, Jones KW, Renlund DG, Bair TL, Bunch TJ, et al. Early postoperative use of unfractionated heparin or enoxaparin is associated with increased surgical re-exploration for bleeding. Ann Thorac Surg. 2005;80:518-22.

25. Biancari F, Mikkola R, Heikkinen J, Lahtinen J, Kettunen U, Juvonen T. Individual surgeon's impact on the risk of re-exploration for excessive bleeding after coronary artery bypass surgery. J Cardiothorac Vasc Anesth. 2012;26:550-6.

26. Hall TS, Brevetti GR, Skoultchi AJ, Sines JC, Gregory P, Spotnitz AJ. Re-exploration for hemorrhage following open heart surgery differentiation on the causes of bleeding and the impact on patient outcomes. Ann Thorac Cardiovasc Surg. 2001:7:352-7.
Key Words: atrial fibrillation, bleeding, length of stay, morbidity, readmission, reexploration, survival

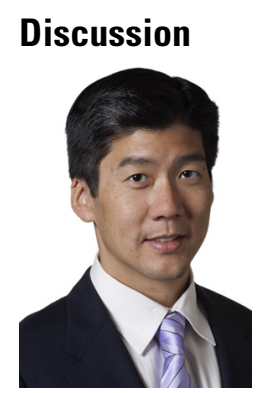

Dr S. C. Malaisrie (Chicago, Ill). I'd like to congratulate Dr Ruel for a fantastic project and also the Association for giving me the opportunity to discuss this paper. I've had the opportunity to review the manuscript. Dr Ruel studied the risk factors and impact of reexploration for bleeding. Data was analyzed in more than 16,000 consecutive cases at the University of Ottawa Heart Institute. Preoperative characteristics included a mean age of 65 and $71 \%$ male. Reexploration for bleeding occurred in $4.2 \%$ of cases and was associated with a $12 \%$ perioperative mortality, corresponding to an odds ratio of 4.1. Reexploration was also associated with increased length of stay, postoperative atrial fibrillation, renal failure, ICU readmission, and wound infections.

Risk factors for reexploration included TV repair, on-pump CABG, cardiopulmonary bypass duration, emergency status, low BSA. A very novel finding was the association of lowest hematocrit on cardiopulmonary bypass of $<24 \%$. Dr Ruel's conclusions are that reexploration is associated with increased mortality and morbidity and that a potential modifiable risk factor is avoidance of anemia during cardiopulmonary bypass.

I have 3 questions for Dr Ruel. I'll give him all 3 at one time. The first question is the study found that reexploration for bleeding is an independent determinant of perioperative mortality, with an odds ratio of 4.1. How did you control for bleeding and also pericardial tamponade? To clarify my question, perhaps the need for reexploration for bleeding is a marker for major bleeding and subsequent need for blood transfusion, which is a known determinant for mortality. Similarly, in patients with pericardial tamponade, perhaps it's the resulting shock and possible cardiac arrest in the ICU that is a true determinant of mortality.

Second, you state that the lowest hematocrit of less than $24 \%$ is associated with reexploration and imply that intraoperative anemia should be avoided in order to reduce the risk of reexploration. How do you explain the mechanism of intraoperative anemia leading to reexploration for bleeding?

My final question has to do with guidelines, which we all love. The 2011 STS and Society of CV Anesthesiologist Guidelines on Blood Conservation, with Victor Ferraris as the first author, provide the following class IIa recommendation: during cardiopulmonary bypass with moderate hypothermia, transfusion of fewer than 6 units of red cells, corresponding to a hematocrit of 18 , is reasonable. 
Perhaps more applicable to the patients that you and I see, a class IIb recommendation is for patients on cardiopulmonary bypass at risk for critical end organ ischemia and injury, transfusions to keep hemoglobin above 7 , which corresponds to a hematocrit of 21 , may be considered.

Dr Ruel, how do you reconcile your findings that a hematocrit threshold of $24 \%$ is more appropriate than what these guidelines recommend? Again, I'd like to thank you for an excellent, excellent project. Thank you.

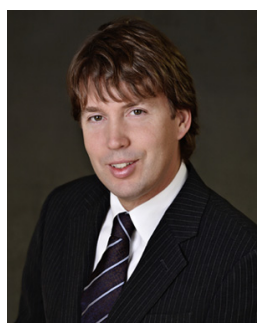

Dr Ruel (Ottawa, Ontario, Canada). Chris, thank you. These are excellent questions, and I think they go straight to the essence of this study. Regarding your first question, you're absolutely right. The mortality and morbidity of reexploration are unlikely to be totally related to the act of reopening someone for bleeding, but also are effected by what has led to this reexploration. However, these 2 issues cannot completely be separated out in any form or fashion. What's important here is that the bleeding, the tamponade, and the reopening in many instances can be avoided. This should be the topic of further research, given that we know that that constellation of whatever surrounds reexploration for bleeding is lethal. Indeed, it may not be the reopening itself, but the reopening likely has an impact of its own as well.

Certainly what we've observed with regard to induction of atrial fibrillation, additional inflammation, and surgical wound infection may be related, at least in part, to the surgical act of reexploration for bleeding.
Regarding your second question about the association between hemodilution and reexploration for bleeding, I think that the answer might lie in coagulopathy. Some smaller antecedent reports have suggested that the mortality and morbidity of reopening for medically caused postoperative bleeding exceeds than that of reopening for a surgical etiology. Here a low hematocrit might be a correlate or even have a mechanistic role in identifying patients with a sole or extra element of coagulopathy.

To address your third question, with regard to modifying the guidelines, I would answer first with the wellknown adage that guidelines are like sausage: if we knew what goes in them, we wouldn't love them so much. Certainly, the hematocrit nadir and the transfusion thresholds are constantly being reevaluated. On March 12, 2016, the latest TITRe 2 study came out of the United Kingdom, showing (on careful reading) that patients who were exposed to a liberal transfusion scheme did better than those on a restrictive transfusion scheme. Patients transfused with $9 \mathrm{~g} / \mathrm{dL}$ of hemoglobin did better than those transfused with $7.5 \mathrm{~g} / \mathrm{gL}$ in terms of mortality and the composite outcome. And even from a cost effectiveness standpoint, the trial was completely neutral. In other words, if they saved money with regards to blood transfusion, they spent more because those patients on a restrictive transfusion strategy had more complications, and the system had to pay for them.

So I think the jury is still out on this issue of nadir hematocrit, and as you said, these are class II recommendations, which are still very malleable at this stage. 